\title{
Blood Flow Velocity Prediction in Aorto-iliac Stent Grafts Using Computational Fluid Dynamics and Taguchi Method
}

\author{
Albert Y. Chong ${ }^{\mathrm{a}}$, Barry J. Doyle ${ }^{\mathrm{b}, \mathrm{c}, \mathrm{d}}$, Shirley Jansen ${ }^{\mathrm{b}, \mathrm{e}}$, Stefan Ponosh ${ }^{\mathrm{e}}$, Julien Cisonni ${ }^{\mathrm{f}}$, Zhonghua Sun ${ }^{\mathrm{a}, *}$

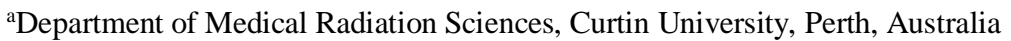 \\ ${ }^{b}$ Harry Perkins Institute of Medical Research, Perth, Australia \\ 'School of Mechanical and Chemical Engineering, University of Western Australia, Perth, Australia \\ ${ }^{\mathrm{d} B r i t i s h}$ Heart Foundation Centre for Cardiovascular Sciences, University of Edinburg, UK \\ 'Sir Charles Gairdner Hospital, Perth, Australia \\ fDepartment of Mechanical Engineering, Curtin University, Perth, Australia
}

\section{ARTICLE INFO}

Keywords:

Analysis of variance

Aortoiliac Stenting

Computational fluid dynamics

Multiple linear regressions

Orthogonal array

Peak Systolic Velocity

Taguchi method

\section{ASBRACT}

Covered Endovascular Reconstruction of Aortic Bifurcation (CERAB) is a new technique to treat extensive aortoiliac occlusive disease with covered expandable stent grafts to rebuild the aortoiliac bifurcation. Post stenting Doppler ultrasound (DUS) measurement of maximum peak systolic velocity $\left(\mathrm{PSV}_{\max }\right)$ in the stented segment is widely used to determine patency and for follow up surveillance due to the portability, affordability and ease of use. Anecdotally, changes in haemodynamics created by CERAB can lead to falsely high PSV $_{\max }$ requiring CT angiography (CTA) for further assessment. Therefore, the importance of DUS would be enhanced with a proposed PSV $_{\max }$ prediction tool to ascertain whether $\mathrm{PSV}_{\max }$ falls within the acceptable range of prediction. We have developed a prediction tool based on idealized models of aortoiliac bifurcations with various infra-renal PSV ( $\mathrm{PSV}_{\text {in }}$ ), iliac to aortic area ratios $(\mathrm{R})$ and aortoiliac bifurcation angles $(\alpha)$. Taguchi method with orthogonal arrays $(\mathrm{OA})$ was utilized to minimize the number of Computational Fluid Dynamics (CFD) simulations performed under physiologically realistic conditions. Analysis of Variance (ANOVA) and Multiple Linear Regression (MLR) analyses were performed to assess Goodness of fit and to predict $\mathrm{PSV}_{\max }$. $\mathrm{PSV}_{\text {in }}$ and $\mathrm{R}$ were found to contribute $94.06 \%$ and $3.36 \%$ respectively to $\mathrm{PSV}_{\max }$. The Goodness of fit based on adjusted $\mathrm{R}^{2}$ improved from 99.1\% to $99.9 \%$ based on linear and exponential functions. The PSV $\mathrm{Pax}_{\max }$ predictor based on the exponential model was evaluated with sixteen patient specific cases with a mean prediction error of $9.9 \%$ and standard deviation of $6.4 \%$. Eleven out of sixteen cases (69\%) in our current retrospective studies would have avoided CTA if the proposed predictor was used to screen out DUS measured PSV $\mathrm{V}_{\max }$ with prediction error greater than $15 \%$. The predictor therefore has the potential to be used as a clinical tool to detect PSV $\mathrm{max}_{\max }$ more accurately post aortoiliac stenting and might reduce diagnostic errors and avoid unnecessary expense and risk from CTA follow-up imaging.

\section{Introduction}

Cardiovascular disease (CVD) is a leading cause of death globally. In Australia, it accounted for $34 \%$ of all deaths in 2008 [1]. Peripheral arterial disease (PAD) is part of a broad spectrum of atherosclerotic cardiovascular diseases that affect the coronary, cerebrovascular, visceral, aortoiliac, and infrainguinal vascular bed. PAD affects 8 to 10 million people

\footnotetext{
*Corresponding author: Tel: +61-8-9266-7509, Fax: +61-8-9266-2377 Email address: z.sun@curtin.edu.au
}

per year in the United States alone [2]. Aortoiliac Occlusive Disease (AIOD) is a subset of PAD involving an atherosclerotic occlusion of the infra-renal aorta, common iliac arteries, or both. Treatment of AIOD can be performed either via open surgical repair or by minimal invasive endovascular stenting. Most physicians are now using endovascular approaches to treat most levels of AIOD $[3,4]$ with covered or bare stents. There are several configurations available; some include the newer technique of relining the 
entire bifurcation with stents (Covered Endovascular Reconstruction of the Aortic Bifurcation (CERAB)). Recent studies indicate good patency and clinical outcome with covered stents [4-7].

While CERAB has proven to be effective in treating AIOD [4], its haemodynamic effects are not fully understood. There are instances where measurements using ultrasound indicate higher than expected $\mathrm{PSV}_{\max }$ usually indicating stenosis, but subsequent CT Angiography (CTA) reveals excellent patency and absence of restenosis. To address similar concerns, CFD and predictive value of PSV were evaluated and in some cases, treatment plans were proposed for clinical applications [8-11]; and to address our specific issue , a PSV $\max$ predictor was developed using CFD, Taguchi method and Multiple Linear Regression (MLR) with the aim of defining the "new normal” post CERAB and avoiding the requirement for CTA during follow up.

\section{Methods}

\subsection{Design of Experiments (DOE)}

Taguchi orthogonal array (OA) takes the form $\mathrm{L}_{\mathrm{a}}\left(\mathrm{B}^{\mathrm{c}}\right)$. The 'a' subscript of Latin square $L$ represents the number of experimental runs or simulations. B is the number of levels in each column and its c exponent is the number of columns in the array. DOE using Taguchi method can help researchers significantly reduce the time required for experimental or simulation investigations. $\mathrm{L}_{16}\left(2^{15}\right)$ was used by Qi et al [12] to analyze the sensitivity of a middle ear finite-element model from nine parameters whereas $\mathrm{L}_{8}\left(2^{4}\right)$ was used by Trabelsi et al [13] to study the influence of four control factors and their interactions on Vero cell growth in vaccine production and $\mathrm{L}_{12}$ $\left(2^{11}\right)$ was applied on a Skin Burn Injury Prediction model from 11 control factors by Autrique and Lormel [14]. In our studies, $\mathrm{L}_{8}\left(2^{7}\right)$ was used to analyze the effects of three control factors namely, infra-renal inlet velocity PSV (PSV in), iliac to aortic area ratios $(\mathrm{R})$ and aortoiliac bifurcation angles $(\alpha)$; and their two-way interactions on $\mathrm{PSV}_{\max }$ in a human aortoiliac bifurcation. Appendix A provides a detailed description of DOE planning, OA selection, and design of the simulation studies.

\subsection{Computational Fluid Dynamics (CFD)}

Computer Aided Design (CAD) software SolidWorks (Dassault Systems, Velizy, France) and Ansys SpaceClaim (ANSYS, Canonberg, PA, USA) were used to create idealized 3D CAD models to mimic the lumen at the aortic bifurcation treated with CERAB using Atrium V12 stents manufactured by Atrium Medical Corporation (Hudson, New Hamsphire, USA). The 3D CAD models were built based on realistic models of still and X-ray images from Groot Jebbink et al [15] and the overall geometrical dimensions were derived from Grimme [4]. Surface meshes were created from 3D CAD models using ANSYS 17.0 Fluent meshing tool and subsequently discretized into polyhedral elements.

The governing equations of the fluid domain were computationally solved using ANSYS Fluent 17.0, a finite volume method CFD solver. Cardiac blood flow was simulated based on the following realistic physiological conditions: 
- Blood density of $1060 \mathrm{~kg} / \mathrm{m}^{3}$

- Blood Flow was considered to be lamina incompressible and isotropic.

- Blood was assumed to be a Non-Newtonian Fluid, its viscosity was estimated using the Carreau Model [16] where $\lambda=3.313 \mathrm{~s}, \mathrm{n}=0.3568$, $\mu_{0}=0.056$ pa-s, $\mu_{\infty}=0.0035$ pa-s

- Non-slip conditions were applied at the artery walls

- Triphasic pulsatile waveform was applied at the inlet which was obtained from Fraser et al [17] based on 21 subjects via User Define Function(UDF) in ANSYS Fluent.

- An entrance length equal to nine times the inlet diameter of $20 \mathrm{~mm}(9 \times 20 \mathrm{~mm}=180 \mathrm{~mm})$ was introduced to obtain a realistic velocity profile in the infra-renal aortic region [18].

- The exit length was set at $200 \mathrm{~mm}$ which is more than 16 times outlet diameter (D) [19] so that the flow can return to a nearly fully developed state and that the outlet boundary does not affect the upstream flow.

- A constant gauge pressure of $100 \mathrm{mmHg}$ (13332 Pa) was applied at the outlets [17].

CFD simulations were conducted on volume mesh generated from idealized geometry according to the parameter setting as outline in Appendix A, Table A.3. Steady state simulation was first performed using laminar model and a semi-implicit SIMPLEC solution method in ANSYS FLUENT 17.0 solver with default solution controls. Under relaxation factors for pressure and momentum were fine-tuned to 0.36 and 0.78 respectively to reduce the number of iterations to reach steady state convergence and were found to be optimal and subsequently used in all simulations. Transient simulation with bounded second order implicit method, 0.01 second fixed time-step were used and a total of three cardiac cycles ( $3 \mathrm{x}$ $0.93 \mathrm{~s})=2.79 \mathrm{~s}$ or 279 number of time-steps were performed for each simulation.

Appendix B outlines the details of inlet boundary condition, determination of entrance length, grid independence and periodicity convergence tests. 


\subsection{Acquisition of Patient Specific Data}

All patient data were de-identified in compliance with Human Research Ethics requirements. Retrospective patient spectral Doppler data for infra-renal aortic $\mathrm{PSV}_{\text {in }}$ and intrastent $\mathrm{PSV}_{\max }$ from common iliac arteries were obtained using Philips CX50 Ultrasound Machine (Philips Healthcare, Amsterdam, Netherlands) with a 5-1 $\mathrm{MHz}$ curved probe operating in pulsed wave mode. Fig. 1 shows a typical measurement of Common Iliac Artery (CIA) velocity.



Fig. 1. Typical Doppler Ultrasound Measurement of CIA Velocity

The associated CTA images for the aortoiliac bifurcation were obtained using GE Medical System LightSpeed VCT CT Scanner (GE Healthcare, Chicago, Illinois, USA) with $512 \mathrm{x}$ 512 resolution and $0.625 \mathrm{~mm}$ slice thickness. From the CTA images, linear and angular measurement tools in InterViewer software version 4.9.1-P132 (Intelerad Medical Systems, Montreal, Quebec, Canada) were used to determine bifurcation angle $(\alpha)$, aortic diameter and left and right iliac diameters as shown in Fig.2. The aortic diameter was measured immediately below the two renal arterials whereas the iliac diameters were measured just before they branched into the external and internal iliac arteries. To minimize measurement error, six sets of measurements per patient were taken. The first set of measurements was taken from the front coronal plane and two subsequent sets of measurements from adjacent rotated slices. Likewise three more sets of measurements were taken from the back coronal plane. The iliac to aortic area ratio $(\mathrm{R})$ were then calculated as $\left(\mathrm{D}_{2}{ }^{2}+\right.$ $\left.\mathrm{D}_{3}{ }^{2}\right) / \mathrm{D}_{1}{ }^{2}$, as defined in Appendix A, Fig. A.1.



Fig.2. Angle and Diameters Measurements

\subsection{Statistical Analysis}

In statistics, multiple linear regression (MLR) is an approach for modelling the relationship between a dependent variable and two or more independent variables. In our studies, SPSS version 23, a statistical analysis software from IBM (Armonk, New York, United States) was used to establish a mathematical function between dependent variable $\mathrm{PSV}_{\max }$ and independent variables $\mathrm{PSV}_{\mathrm{in}}, \mathrm{R}$ and $\alpha$. A simple linear function MLR model with step-wise elimination method was applied. The constant and coefficients from the MLR output were used to determine the relationship between the 
dependent variable $\mathrm{PSV}_{\max }$ and independent variables $\mathrm{PSV}_{\text {in }}$, $\mathrm{R}$ and $\alpha$. Subsequently, an exponential function was applied. Adjusted $\mathrm{R}^{2}$, a measure of Goodness of fit was used to compare how well the independent variables describe the model where 1 is perfect fit. The purpose of the Analysis of Variance (ANOVA) is to determine which independent variable, or interactions between independent variables, significantly affects the dependent variable. In addition to DOF, Sum of Squares (SS) and Mean of Squares (MS), FRatio, p-value and Contribution (C \%) associated with each independent variable was reviewed. The ANOVA was performed for a confidence level of $95 \%$. The p value for each independent variable was calculated with less than 0.05 considered statistically significant. 


\section{Results}

\subsection{CFD Simulation Results}

CFD simulations from eight combinations of $\mathrm{PSV}_{\text {in }}, \alpha, \mathrm{R}$ and their interactions as defined in Appendix A, TABLE A.3 were performed using Fluent CFD solver. Fig. 3 shows the results of PSV max $_{\text {max }}$ taken at the peak of the third cardiac cycle at time-step 2.0 second as described in Appendix B.

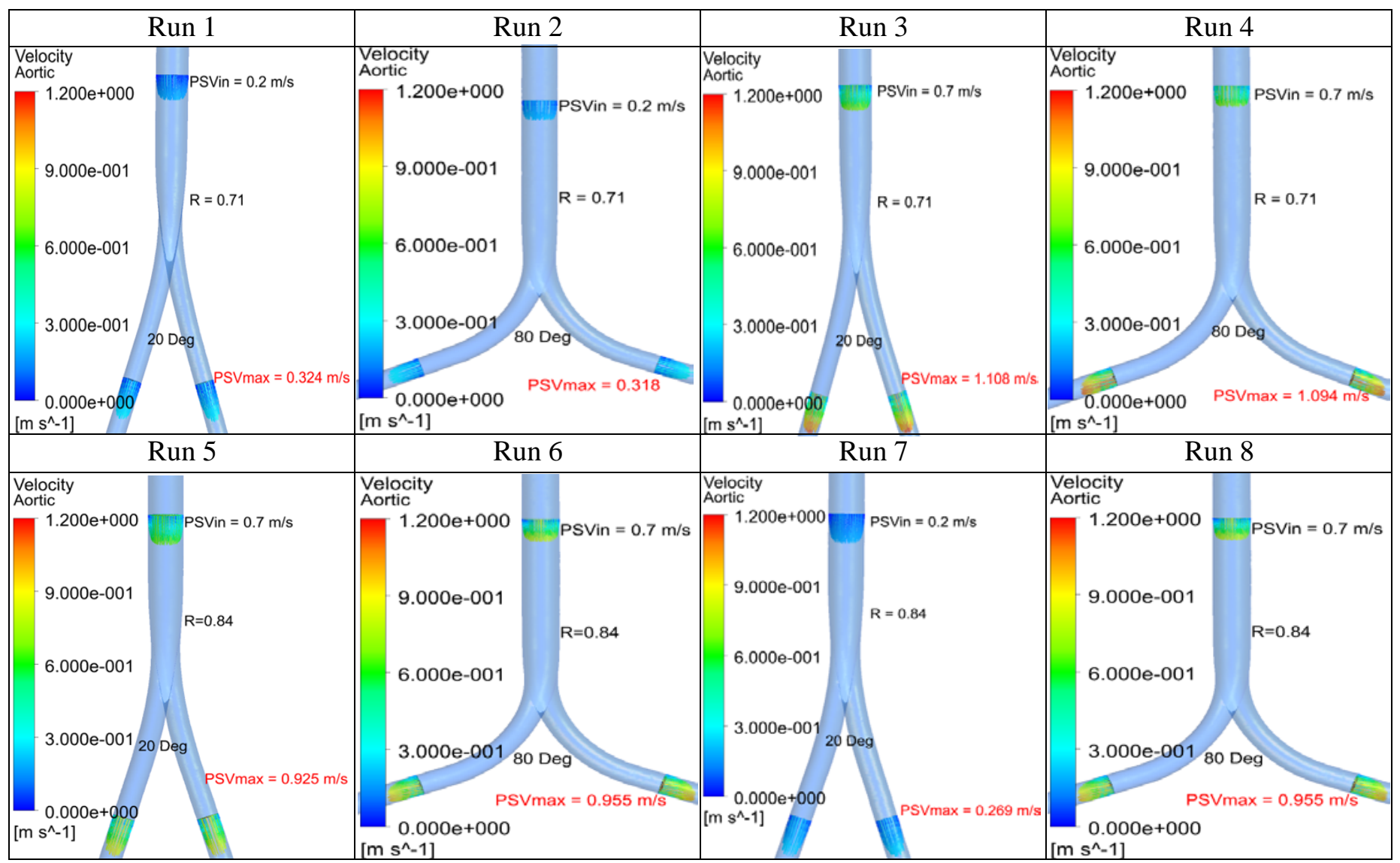

Fig. 3. CFD Simulation Results

\subsubsection{Signal to Noise Ratio Main Effects}

In Taguchi method, Signal to Noise $(\mathrm{S} / \mathrm{N})$ ratio, a measure of robustness, is used to identify control factors that reduce variability in a product or process by minimizing the effects of uncontrollable factors (noise factors). In our study, $\mathrm{PSV}_{\max }$ is considered as larger the better attribute and $\mathrm{S} / \mathrm{N}$ of $\mathrm{PSV}_{\max }=-10 * \log \left(1 / \mathrm{PSV}_{\max } * \mathrm{PSV}_{\max }\right)$. The averages or means of the $\mathrm{S} / \mathrm{N}$ ratio of $\mathrm{PSV}_{\max }$ for each level of control factor are shown in Table 1. Delta is defined as the difference in responses at level 1 and 2; larger Delta implying greater effect of control factor on $\mathrm{PSV}_{\max }$ PSV $_{\text {in }}$ with a Delta of 10.465 ranks the highest followed by R with 1.836 and $\alpha$.with 0.593 . 
Table 1

Response table of main effects

\begin{tabular}{lccccc}
\hline \hline & \multicolumn{2}{l}{ Mean at each level } & & \\
\cline { 2 - 4 } Control Factor & \multicolumn{2}{c}{ Level } & & \\
\cline { 2 - 4 } & 1 & 2 & Delta & Rank \\
\hline A $\quad$ PSV $_{\text {in }}(\mathrm{m} / \mathrm{s})$ & -9.829 & $\mathbf{0 . 6 3 4}$ & 10.465 & 1 \\
\hline B & $\mathrm{R}$ & -3.679 & -5.515 & 1.836 & 2 \\
\hline C $\quad \alpha($ Degree $)$ & -4.893 & -4.300 & 0.593 & 3 \\
\hline \hline
\end{tabular}

\subsubsection{Interaction Effects}

Figs. 4 to 6 show the effects of 2-way interaction between the three control factors. The parallel plot indicates that there is little or no interaction, whereas the size of the angle where the two lines intercept each other indicates the strength of interaction between the two control factors. In our case, there are no interaction effects for 2-way interactions between $\alpha$ and $\mathrm{PSV}_{\text {in }}$; and between $\mathrm{PSV}_{\text {in }}$ and $\mathrm{R}$ whereas there is a weak interaction effect between $\mathrm{R}$ and $\alpha$.

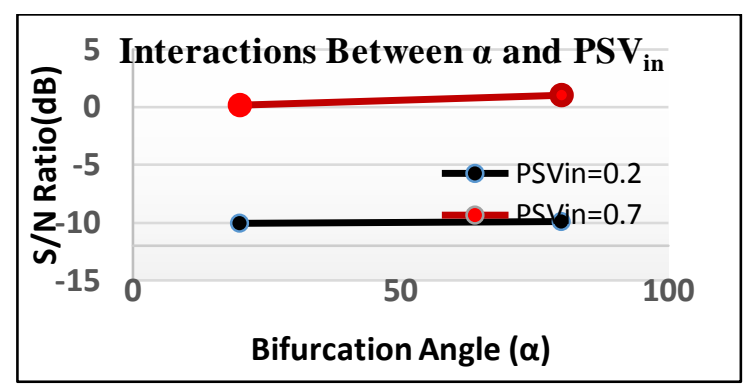

Fig. 4. Interactions between $\alpha$ and $\mathrm{PSV}_{\text {in }}$

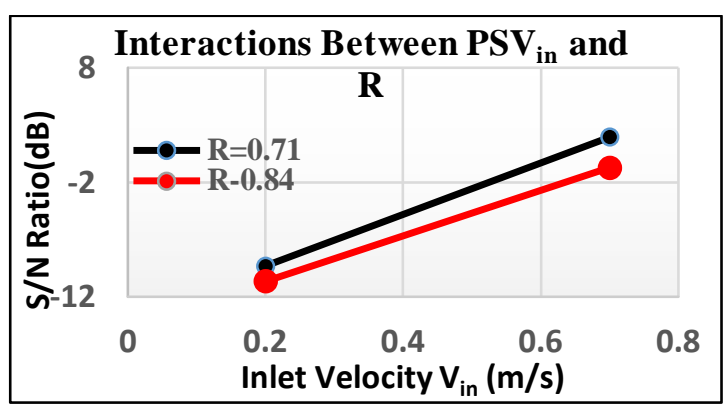

Fig. 5. Interactions between PSVin and R

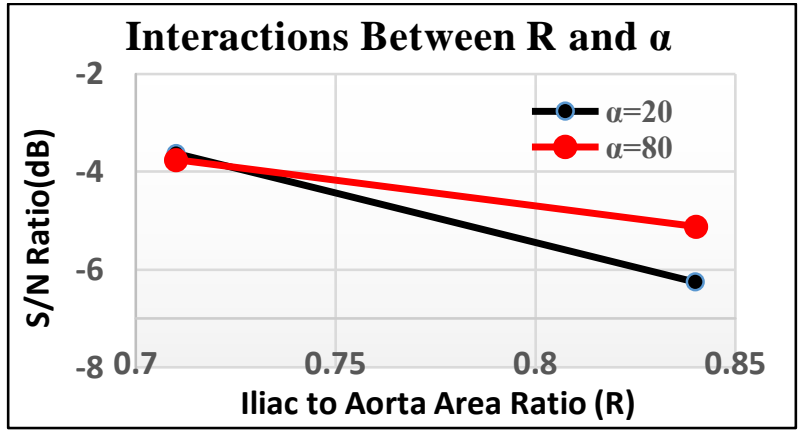

Fig. 6. Interactions between $R$ and $\alpha$

\subsubsection{Analysis of Variance}

Table 2 shows the results of ANOVA for S/N ratio of $\mathrm{PSV}_{\max }$. Independent variables $\mathrm{PSV}_{\text {in }}$ and $\mathrm{R}$ were found to be significant with p-values of $<0.001$ and 0.046 respectively. Whereas the p-values of independent variable $\alpha, 2$-way and 3way interactions were found to be greater than 0.05 therefore were deemed to be insignificant. The contributions were in the following order: $\mathrm{PSV}_{\text {in }}$ (94.06\%), R (3.36\%) and the 3-way interactions among $\mathrm{PSV}_{\mathrm{in},} \mathrm{R}$ and $\alpha(1.57 \%)$.

Table 2

ANOVA table for $\mathrm{S} / \mathrm{N}$ ratio of $\mathrm{PSV}_{\max }$

\begin{tabular}{|c|c|c|c|c|c|c|}
\hline Factor & $\begin{array}{l}\mathbf{D} \\
\mathbf{O} \\
\mathbf{F}\end{array}$ & $\begin{array}{l}\text { Sum of } \\
\text { Square }\end{array}$ & $\begin{array}{c}\text { Mean } \\
\text { Square }\end{array}$ & $\mathbf{F}$ & p-value & $\begin{array}{l}\text { Contri- } \\
\text { bution } \\
\text { (C \%) }\end{array}$ \\
\hline Vin & 1 & 224.19 & 224.19 & 159.04 & 0.000228 & $94.06 \%$ \\
\hline $\mathbf{R}$ & 1 & 8.0137 & 8.0137 & 5.6849 & 0.045635 & $3.36 \%$ \\
\hline$\alpha$ & 1 & 0.5108 & 0.5108 & 0.3624 & 0.579657 & $0.21 \%$ \\
\hline$P \mathrm{PV}_{\text {in }} \mathrm{XR}$ & 1 & 0.8479 & 0.8479 & 0.6015 & 0.481310 & $0.36 \%$ \\
\hline $\mathbf{R x a}$ & 1 & 0.8038 & 0.8038 & 0.5702 & 0.492208 & $0.34 \%$ \\
\hline$\alpha x P S V_{\text {in }}$ & 1 & 0.2463 & 0.2463 & 0.1747 & 0.697392 & $0.10 \%$ \\
\hline$P S V_{\text {in }} x \mathbf{R x} \alpha$ & 1 & 3.7406 & 3.7406 & 2.6536 & 0.178649 & $1.57 \%$ \\
\hline Error & $\mathbf{0}$ & 0 & - & & & \\
\hline Total & $\begin{array}{l}7 \\
4\end{array}$ & $\begin{array}{r}238.35 \\
5.6386\end{array}$ & 14097 & 1.0000 & & $237 \%$ \\
\hline
\end{tabular}

\subsubsection{Predictive Models}

Mathematical models are useful tools to determine the relationship between a dependent variable and multiple independent variables and can therefore serve as predictive models. MLR analysis using SPSS was first applied to linear 
function. From the output of SPSS MLR analysis, the independent variable $\alpha$ was ignored after step-wise elimination due to its insignificance. The constant was 0.684 and the coefficients for $\mathrm{PSV}_{\text {in }}$ and $\mathrm{R}$ of the predictive model were 1.461 and -0.894 respectively. Its equation was identified as follows:

$$
\mathrm{PSV}_{\max } \text {-hat }=0.684+1.461 \mathrm{PSV}_{\text {in }}-0.894 \mathrm{R}
$$

where “-hat” stands for predicted value. Adjusted $\mathrm{R}^{2}$ for the linear model was 0.991. Two way interactions and $\alpha$ were ignored when investigating exponential function since they were found to be insignificant in section 3.1.3. The exponential equation was postulated as:

$$
\begin{aligned}
& \mathrm{PSV}_{\max }=\mathrm{C} \cdot \mathrm{PSV}_{\text {in }}{ }^{\mathrm{x}} \cdot \mathrm{R}^{\mathrm{y}} \\
& \ln \left(\mathrm{PSV}_{\max }\right)=\ln (\mathrm{C})+\mathrm{x} \cdot \ln \left(\mathrm{PSV}_{\mathrm{in}}\right)+\mathrm{y} \cdot \ln (\mathrm{R})
\end{aligned}
$$

$\ln \left(\mathrm{PSV}_{\max }\right)$ was then considered as the dependent variable whereas $\ln \left(\mathrm{PSV}_{\text {in }}\right)$ and $\ln (\mathrm{R})$ were considered as independent variables. MLR analysis was then performed and SPSS yielded constant $\ln (C)=0.117$, therefore $C=e^{0.117}=1.124$, whereas coefficients for $\ln \left(\mathrm{PSV}_{\text {in }}\right)$ and $\ln (\mathrm{R})$ were 0.989 and 0.979 respectively therefore the predictive equation was identified as follows:

$$
\mathrm{PSV}_{\max } \text {-hat }=1.124 \mathrm{PSV}_{\text {in }}{ }^{0.989} \cdot \mathrm{R}^{0.979}
$$

Adjusted $\mathrm{R}^{2}$ for the exponential function MLR model was found to be 0.999 which was a $0.8 \%$ improvement from using linear function.

\subsection{Measurement Results of Patient Data}

Sixteen sets of DUS and CTA images were provided by collaborating surgeons in Western Australia for retrospective evaluation. All CTA images were acquired with $0.625 \mathrm{~mm}$ slice thickness allowing generation of volumetric data with superior resolution. Diameter and angle measurements as described in section 2.4 were performed on these CTA images.

Table 3 shows patient data with $\mathrm{R}$ on column 5, bifurcation

\begin{tabular}{|c|c|c|c|c|c|c|}
\hline \multirow[b]{2}{*}{ 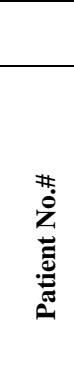 } & \multicolumn{5}{|c|}{ Measurements from CTA Images } & $\begin{array}{c}\text { Ultrasound } \\
\text { Measurements }\end{array}$ \\
\hline & 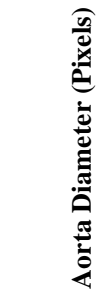 & 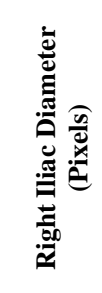 & 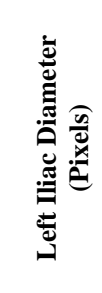 & 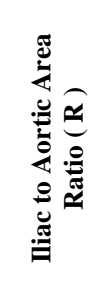 & 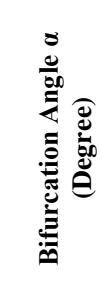 & 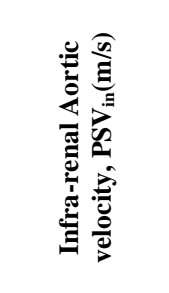 \\
\hline 1 & 24.82 & 12.27 & 16.16 & 0.67 & 47.27 & 1.00 \\
\hline 2 & 11.25 & 7.44 & 6.18 & 0.74 & 47.81 & 0.89 \\
\hline 3 & 5.73 & 3.74 & 3.87 & 0.88 & 34.41 & 1.75 \\
\hline 4 & 12.12 & 6.12 & 5.57 & 0.47 & 39.78 & 0.58 \\
\hline 5 & 31.59 & 18.71 & 18.12 & 0.68 & 37.04 & 0.77 \\
\hline 6 & 15.95 & 8.03 & 7.74 & 0.49 & 53.73 & 0.54 \\
\hline 7 & 11.52 & 7.51 & 7.52 & 0.85 & 51.81 & 1.35 \\
\hline 8 & 4.46 & 2.96 & 3.10 & 0.92 & 44.49 & 2.01 \\
\hline 9 & 12.54 & 8.17 & 7.62 & 0.79 & 48.89 & 0.87 \\
\hline 10 & 19.42 & 6.48 & 6.31 & 0.22 & 71.30 & 0.29 \\
\hline 11 & 12.76 & 8.13 & 7.29 & 0.73 & 45.14 & 0.86 \\
\hline 12 & 9.69 & 3.85 & 3.82 & 0.31 & 91.35 & 0.88 \\
\hline 13 & 18.50 & 10.33 & 9.96 & 0.60 & 41.09 & 0.90 \\
\hline 14 & 8.65 & 4.89 & 4.73 & 0.62 & 34.07 & 0.91 \\
\hline 15 & 15.69 & 9.56 & 7.87 & 0.62 & 68.35 & 0.98 \\
\hline 16 & 13.02 & 7.49 & 6.67 & 0.59 & 40.02 & 1.52 \\
\hline
\end{tabular}
angle $\alpha$ on column 6 and $\mathrm{PSV}_{\text {in }}$ on column 7.

Table 3

Patient data and corresponding CTA and ultrasound measurements

\subsection{Prediction Results from the Predictive Model}

Using equation (1) and equation (4), predicted $\mathrm{PSV}_{\max }$ from linear function analysis and exponential function analysis were compared against DUS measured PSV $\mathrm{Pax}_{\max }$ as shown in Table 4. The mean prediction error and standard deviation reduced from $17.4 \%$ and $14.8 \%$ in the linear 
function predictor to $9.9 \%$ and $6.4 \%$ in the exponential function predictor respectively.

Table 4

Patient Specific Predictions

\begin{tabular}{|c|c|c|c|c|c|}
\hline \multirow{2}{*}{\multicolumn{2}{|c|}{ 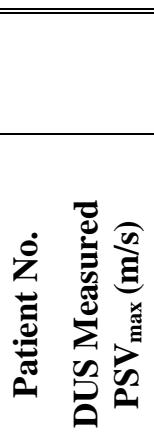 }} & \multicolumn{2}{|c|}{$\begin{array}{c}\text { Linear } \\
\text { Function } \\
\text { MLR } \\
\end{array}$} & \multicolumn{2}{|c|}{$\begin{array}{c}\text { Exponential } \\
\text { Function MLR }\end{array}$} \\
\hline & & 绨 & 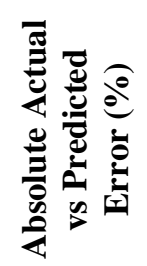 & 惫 & 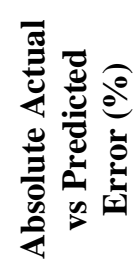 \\
\hline
\end{tabular}

\begin{tabular}{|c|c|c|c|c|c|}
\hline 1 & 1.60 & 1.54 & 3.7 & 1.66 & 4.0 \\
\hline 2 & 1.49 & 1.33 & 11.1 & 1.35 & 9.7 \\
\hline 3 & 2.27 & 2.46 & 8.3 & 2.22 & 2.4 \\
\hline 4 & 1.71 & 1.55 & 9.3 & 1.75 & 2.4 \\
\hline 5 & 1.68 & 1.10 & 34.8 & 1.37 & 18.2 \\
\hline 6 & 1.53 & 1.20 & 21.6 & 1.27 & 17.2 \\
\hline 7 & 1.49 & 1.02 & 31.5 & 1.23 & 17.5 \\
\hline 8 & 1.95 & 1.90 & 2.4 & 1.77 & 9.1 \\
\hline 9 & 2.87 & 2.80 & 2.4 & 2.43 & 15.2 \\
\hline 10 & 1.32 & 1.26 & 4.9 & 1.23 & $\begin{array}{ll}6.5 \\
\end{array}$ \\
\hline 11 & 1.89 & 0.88 & 53.6 & 1.46 & 23.0 \\
\hline 12 & 1.39 & 1.29 & 7.2 & 1.32 & 5.2 \\
\hline 13 & 2.42 & 1.55 & 35.8 & 2.21 & 8.6 \\
\hline 14 & 1.80 & 1.45 & 19.3 & 1.67 & 7.2 \\
\hline 15 & 1.77 & 1.45 & 18.0 & 1.64 & 7.6 \\
\hline 16 & 2.75 & 2.36 & 14.2 & 2.85 & 3.7 \\
\hline \multicolumn{2}{|c|}{ Mean } & & 17.4 & & 9.9 \\
\hline \multicolumn{2}{|c|}{$\begin{array}{l}\text { Standard } \\
\text { Deviation }\end{array}$} & & 14.8 & & 6.4 \\
\hline
\end{tabular}






Fig. 7. Predicted vs Doppler Ultrasound measured PSVmax Plot

Fig. 7 depicts the relationship between DUS measured and Predicted PSV $V_{\max }$ using exponential function mathematical model as the predictor. If the predicted PSV $\mathrm{max}_{\max }$ is of the same value as the DUS measured PSV $_{\max }$, then the plotted point will lie on the unity line. Otherwise, the point will either lie above the unity line when the predicted value is higher than DUS measured value, or the plotted point will lie below the unity line if the predicted value is lower than the DUS measured value. The $+/-15 \%$ Prediction Error lines serve as the boundary lines for a prediction error $<15 \%$. Blue coloured points are within the $15 \%$ prediction error zone whereas red coloured points are outside the 15\% prediction error zone therefore CTA is recommended for further investigation for restenosis. 


\section{Discussion}

From Taguchi method's main effect analysis in section 3.1.1, $\mathrm{PSV}_{\text {in }}$ with a main effect delta of 10.5 was deemed to be six times more significant than $\mathrm{R}$ with a main effect delta of 1.8. However, from ANOVA analysis in section 3.1.3, $\mathrm{PSV}_{\text {in }}$ and $\mathrm{R}$ were found to contribute $94.06 \%$ and $3.36 \%$ to $\mathrm{PSV}_{\max }$, respectively. This implies that $\mathrm{PSV}_{\text {in }}$ was twenty eight times more significant than $\mathrm{R}$. There seems to be an over-estimation of the contribution from $\mathrm{PSV}_{\text {in }}$ on $\mathrm{PSV}_{\max }$ using ANOVA as compared with Taguchi method. Although CERAB will generally use iliac stents which are the same diameter, asymmetry in iliac diameter may result depending how well they expand in the presence of asymmetric iliac disease. This explains the actual iliac measurement results as shown in Table 3 showing slight asymmetry. Even though we assumed iliac symmetry in the CFD simulations, the predicted PSV $\mathrm{max}_{\max }$ matches well with clinical DUS measurements with a mean prediction error of $9.9 \%$ and a standard deviation of $6.4 \%$. From the plot in Fig. 7, five out of sixteen (31\%) predicted $\mathrm{PSV}_{\max }$ were located outside the $15 \%$ prediction error zone. It is proposed that for future prospective studies, patients with predicted $\mathrm{PSV}_{\max }$ outside this zone are recommended for CTA scan to investigate possible restenosis. This criterion might be used in conjunction with the restenosis definition of a lesion causing a PSV ratio $\geq 2.5$ used by Grimme et al [4] and Diehm et al [20]. If this proposed criterion was adapted, $69 \%$ or eleven out of sixteen patients from these retrospective studies could have avoided CTA.
Incidentally, the five predicted $\mathrm{PSV}_{\max }$ values outside the $15 \%$ prediction error zone were all lower than the DUS measured values as these data points were below the unity line indicating a possible bias in the predictor based on limited data. A larger population will be required to investigate whether the bias is systematic or random. Shakeri et al [21] found that $\alpha$ was an independent and significant predictor of aortoiliac atherosclerosis (model $\mathrm{r}^{2}=0.662, \mathrm{p}=0.027$ ), but both Taguchi method and ANOVA in our current study revealed that $\alpha$ does not significantly affect $\mathrm{PSV}_{\max }$. Even though $\alpha$ does not greatly influence PSVmax in our current studies however, it was reported that low wall shear stress contributes to atherosclerosis [22] .

In this retrospective study, infra-renal aortic, and left and right CIA diameters were determined from CTA images because these measurements were not available from DUS images. For future prospective studies, a protocol will be established to specify aortic and CIA diameter measurements to be taken in addition to $\mathrm{PSV}_{\text {in }}$ and $\mathrm{PSV}_{\max }$ measurements during routine post-procedure DUS follow-up examinations.

It could be argued that a further limitation of our study was to assume rigid walls in the CFD simulations. Although the in vivo situation is more complex than the in vitro one, the changes in vessel compliance from increasing disease severity, calcification and placement of balloon expandable stents are to make the vessel more rigid.

It might be interesting to investigate the impact of creating an interface between the end of the rigid stented iliac artery and a more complaint iliac artery beyond it on PSV $_{\max }$ using Fluid Structure Interaction (FSI) CFD simulations. Since 
aortoiliac reconstruction procedures are relatively new and only some patients have high $\mathrm{PSV}_{\max }$ post procedure, there is a need to collect more patient data for evaluation. Idealized bifurcation models were used in the current CFD simulations studies, further investigations using patient specific bifurcations in CFD simulations are planned to confirm the validity of the predictor. In addition, experimental validation with patient specific flow phantoms will be necessary to validate the accuracy and usefulness of the predictor.

\section{Conclusion}

The $\mathrm{PSV}_{\max }$ was significantly influenced by $\mathrm{PSV}_{\text {in }}$ and $\mathrm{R}$. On the other hand, $\alpha$, two-way and three-way interactions among the three control factors were found to be insignificant. The combination of CFD simulation, Taguchi Method and MLR modelling is potentially a powerful tool to predict $\mathrm{PSV}_{\max }$ in patients treated with an aortoiliac reconstruction procedure; CERAB. The exponential function predictive model with adjusted $\mathrm{R}^{2}$ of $99.9 \%$ was evaluated using sixteen sets of patient specific data with a mean prediction error of $9.9 \%$ and standard deviation of $6.4 \%$ when compared against DUS measured PSV $V_{\max }$. The proposed predictor has a potential to be used as a clinical tool to establish the new normal $\mathrm{PSV}_{\max }$ post aortoiliac stenting procedure and can possibly avoid unnecessary CTA investigation with its attendant cost, radiation exposure and contrast risk in cases where Doppler ultrasound measured PSV $\mathrm{max}_{\operatorname{xax}}$ are found to be high.

\section{Conflict of Interest}

None declared.

\section{Acknowledgment}

The study was supported by the Postgraduate research scholarship from the School of Science, Curtin University.

\section{References}

[1] AIHW 2010. Cardiovascular disease mortality: trends at different ages. Cardiovascular disease series no. 31. Cat. no. CVD 47. Canberra, Australia 2011. <http://www.aihw.gov.au/publicationdetail/?id=6442468344>

L. Norgren, W. R. Hiatt, J. A. Dormandy, M. R. Nehler, K. A. Harris, F. G. R. Fowkes, and R. B. Rutherford, Inter-society consensus for the management of peripheral arterial disease, International angiology : a journal of the International Union of Angiology. 26 (2) (2007) 81.

C. Wooten, M. Hayat, M. Plessis, A. Cesmebasi, M. Koesterer, K.

P. Daly, P. Matusz, R. S. Tubbs, and M. Loukas, Anatomical ignificance in aortoiliac occlusive disease. Clinical Anatomy. 27(8) (2014):1264-1274.

F. A. B. Grimme, P. C. J. M. Goverde, P. J. E. M. Verbruggen, C. J. Zeebregts, M. M. P. J. Reijnen, First Results of the Covered Endovascular Reconstruction of the Aortic Bifurcation (CERAB) Technique for Aortoiliac Occlusive Disease, European Journal of Vascular and Endovascular Surgery. 50 (5) (2015) 638-647.

R. Tewksbury, L. Taumoepeau, A. Cartmill, A. Butcher, T. Cohen, Outcomes of covered expandable stents for the treatment of TASC D aorto-iliac occlusive lesions, Vascular. 23 (6) (2015) 630-636.

[6] F.A.B. Grimme, J.H. Spithoven, C.J. Zeebregts, D.M. Scharn, M.M.J.P. Reijnen, Midterm Outcome of Balloon-Expandable Polytetrafluoroethylene-Covered Stents in the Treatment of Iliac Artery Chronic Occlusive Disease, Journal of Endovascular Therapy, 19 (6) (2012) 797-804. 

Stenosis and Occlusive Disease by Kissing-Stent Technique, Stem Cells International, 2016 (2016) 4035307. L. Goubergrits, E. Riesenkampff, P. Yevtushenko, J. Schaller, U. Kertzscher, A. Hennemuth, F. Berger, S. Schubert, T. Kuehne, MRI-based computational fluid dynamics for diagnosis and treatment prediction: clinical validation study in patients with coarctation of aorta, Journal of Magnetic Resoannce Imaging, 41 (4) (2015) 909916 .

K. Tokunaga, M. Koga, S. Yoshimura, S. Arihiro, R. Suzuki, K. Nagatsuka, K. Toyoda, Optimal Peak Systolic Velocity Thresholds for Predicting Internal Carotid Artery Stenosis Greater than or Equal to $50 \%, 60 \%, 70 \%$, and $80 \%$, Journal of Stroke and Cerebrovascular Diseases. 25 (4) (2016) 921-926.

[10] A. Karthikesalingam, S. Kumar, J.J. Anandarajah, R.J. Hinchliffe, J.D. Poloniecki, M.M. Thompson, P.J. Holt, Predictive Value of Peak Systolic Velocity for the Development of Graft Limb Complications After Endovascular Aneurysm Repair, Journal of Endovascular Therapy, 19 (3) (2012) 428-433.

[11] S.A. Plato Ii, E.A. Kudlaty, M.T. Allemang, D.E. Kendrick, V.L. Wong, J.C. Wang, V.S. Kashyap, Elevated Peak Systolic Velocity and Velocity Ratio from Duplex Ultrasound are Associated with Hemodynamically Significant Lesions in Arteriovenous Access, Annals of Vascular Surgery, 35 (2016) 68-74.

[12] L. Qi, C. S. Mikhael, W. R. J. Funnell, Application of the Taguchi method to sensitivity analysis of a middle-ear finite-element model, in: Proceeding of the $28^{\text {th }}$ Annual Conference of Canadian Medical Biological Engineering Society, 2004, pp.153-156.

[13] K. Trabelsi, S. Rourou, H. Loukil, S. Majoul, H. Kallel, Optimization of virus yield as a strategy to improve rabies vaccine production by Vero cells in a bioreactor, Journal of Biotechnology, 121(2) (2006) 261-271.

[14] L. Autrique, and C. Lormel, Numerical Design of Experiment for Sensitivity Analysis: Application to Skin Burn Injury Prediction, Biomedical Engineering, IEEE Transactions on. 55 (4) (2008) 1279-1290.

[15] E. Groot Jebbink, F. A. Grimme, P. C. Goverde, J. A. van Oostayen, C. H. Slump, M. M. Reijnen, Geometrical consequences of kissing stents and the Covered Endovascular Reconstruction of the Aortic Bifurcation configuration in an in vitro model for endovascular reconstruction of aortic bifurcation, Journal of Vascular Surgery. 61 (5) (2015) 1306-1311.

F. Yilmaz, M. Y. Gundogdu, A critical review on blood flow in large arteries relevance to blood rheology, viscosity models, and physiologic conditions, Korea Australia Rheology Journal. 20 (4) (2008) 197-211.

K. H. Fraser, S. Meagher, J. R. Blake, W. J. Easson, and P. R. Hoskins, Characterization of an Abdominal Aortic Velocity Waveform in Patients with Abdominal Aortic Aneurysm, Ultrasound in Medicine \& Biology. 34 (1) (2008) 73-80.

N. Wood, Aspects of fluid dynamics applied to the larger arteries, J ournal of Theoretical Biology, 199 (2) (1999) 137-161.

J. Ryval, A. G. Straatman, D. A. Steinman, Low Reynolds number modeling of pulsatile flow in a moderately constricted geometry, in Proceedings of Eleventh annual conference the CFD society of Canada, Vancouver, 2003.

N. Diehm, P.M. Pattynama, M.R. Jaff, A. Cremonesi, G.J. Becker, L.N. Hopkins, F. Mahler, A. Talen, J.F. Cardella, S. Ramee, M. van Sambeek, F. Vermassen, G. Biamino, Clinical Endpoints in Peripheral Endovascular Revascularization Trials: a Case for Standardized Definitions, European Journal of Vascular and Endovascular Surgery,36 (4) (2008) 409-419.

A. Shakeri Bavil, R. S. Tubbs, M. M. Shoja, H. Nosratinia, W. J. Oakes, M. Nemati, Aortic Bifurcation Angle as an Independent Risk Factor for aortoiliac occlusive disease. Folia Morphologica. 66(3) (2007) 181-184.

Y. Jiang, K. Kohara, K. Hiwada, Low wall shear stress contributes to atherosclerosis of the carotid artery in hypertensive patients, Hypertension research : official journal of the Japanese Society of Hypertension, 22 (3) (1999) 203-207.

Ö. Smedby, Geometric risk factors for atherosclerosis in the aortic bifurcation: A digitized angiography study, Annals of Biomedical Engineering. 24 (4) (1996) 481-488.

M. S. Phadke, Quality engineering using robust design / Madhav S. Phadke, Englewood Cliffs, N.J.: Englewood Cliffs, N.J. : Prentice Hall, 1989. 
[25] M. Spiegel, T. Redel, Y. J. Zhang, T. Struffert, J. Hornegger, R. G. Grossman, A. Doerfler, C. Karmonik, Tetrahedral vs. polyhedral mesh size evaluation on flow velocity and wall shear stress for cerebral hemodynamic simulation, Computer Methods in Biomechanics and Biomedical Engineering. 14 (1) (2011) 9-22. 


\section{Appendix A: Design of Experiment}

\section{Planning}

The region of interest in our study is the shaded section of aortoiliac bifurcation as outlined in Fig. A.1. Based on literature review, Smedby [23] and Shakeri et al [21] found that iliac to aortic area ratio $R=\left(D 2^{2}+D 3^{2}\right) / D 1^{2}$ and bifurcation angle $(\alpha)$ are potential risk factors for the formation of atherosclerotic plaque in the aortoiliac bifurcation. In addition, Fraser et al [17] have characterized the abdominal aortic velocity or infra-renal Peak Systolic Velocity $\left(\mathrm{PSV}_{\text {in }}\right)$ for in vitro and in silico investigations. Table A.1 shows the range of these three parameter values obtained in literature $[14,17,23]$ describing the aortoiliac geometry and physiology.

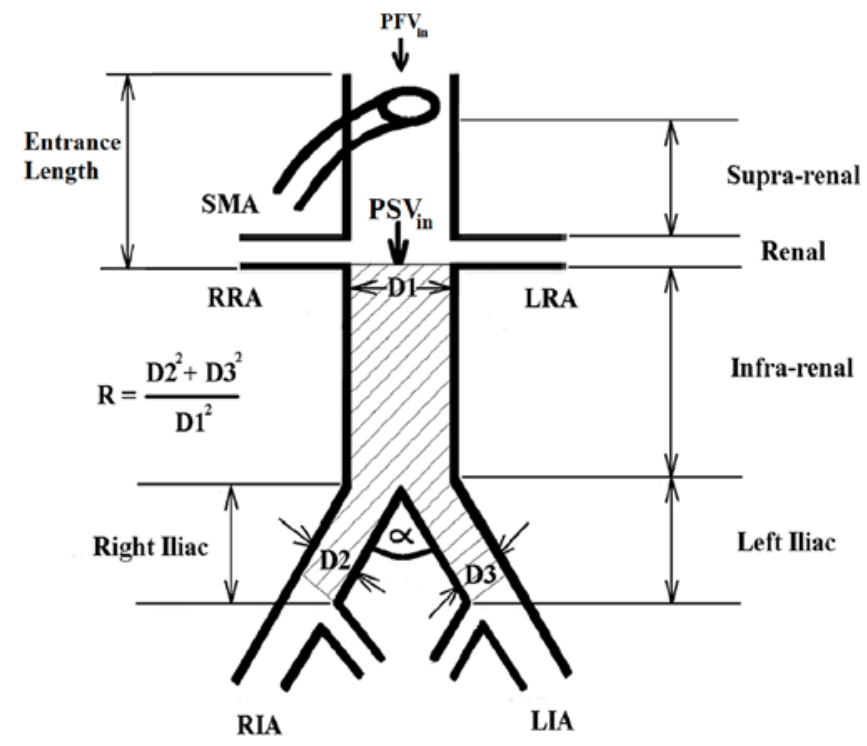

Fig. A.1. A Basic Human Aortoiliac Bifurcation Model
Table A.1:

Aortoiliac bifurcation geometry and physiology from references

\begin{tabular}{|c|c|c|c|c|c|c|c|}
\hline $\begin{array}{c}\text { Parameter/ } \\
\text { Control } \\
\text { Factor } \\
\end{array}$ & Symbol & Unit & Authors & $\begin{array}{l}\text { Mean } \\
\text { Value }\end{array}$ & $\begin{array}{l}\text { Std } \\
\text { Dev }\end{array}$ & $\begin{array}{c}\text { Upper } \\
\text { Limit } \\
(p=0.05)\end{array}$ & $\begin{array}{c}\text { Lower } \\
\text { Limit } \\
(p=0.05)\end{array}$ \\
\hline $\begin{array}{c}\text { Infra-Renal } \\
\text { PSV }\end{array}$ & PSV $_{\text {in }}$ & $(\mathrm{m} / \mathrm{s})$ & $\begin{array}{c}\text { Fraser } \\
\text { et al }\end{array}$ & 0.454 & 0.128 & 0.2 & 0.7 \\
\hline $\begin{array}{c}\text { Iliac to } \\
\text { Aortic Area } \\
\text { Ratio }\end{array}$ & $\mathbf{R}$ & $\begin{array}{c}\text { Dimension- } \\
\text { less }\end{array}$ & Smedby & 0.78 & 0.038 & 0.71 & 0.84 \\
\hline $\begin{array}{c}\text { Bifurcation } \\
\text { Angle }\end{array}$ & $\mathbf{A}$ & Degree & $\begin{array}{c}\text { Shakeri } \\
\text { et al }\end{array}$ & 51 & 14 & 20 & 80 \\
\hline
\end{tabular}

CFD solver was used to solve the fluid flow problem governed by Navier -Stokes equations and to determine $\mathrm{PSV}_{\text {max }}$ for each combination of PSV ${ }_{\text {in }}, \mathrm{R}$ and $\alpha$. Since there was no prior knowledge of the potential interaction effects between these three control factors on PSV $\mathrm{V}_{\max }$, their two-way interactions were included in our investigations. To reduce the number of simulations, two levels for each of the control factors were used.

\section{Design}

The outputs from the planning were used as inputs to the design namely,

- Number of control factors to be investigated

- Number of levels for each control factor

- Specific 2-way and 3-way interactions to be investigated

Orthogonal Array (OA) is a partial factorial design used in the design of experiments to minimize the number of experiments or simulations, and yet be able to draw similar conclusions as compared to full factorial experiments. In order to choose a suitable OA, firstly the total Degrees Of Freedom (DOF) need to be counted which dictates the minimum number of simulation runs. One DOF is associated 
with overall mean regardless of the number of control factors being investigated. As a general principle, the number of DOFs associated with a control factor is equal to one less than the number of levels being investigated. The DOF associated with interactions between two control factors is the product of the DOF for each control factor. A suitable OA was selected based on the total DOF. In our case,

Number of control factors $=3$

Number of level per control factor $=2$

Total DOF for 3 control factors $=3 \times(2-1)=3$

Number of Interactions considered $=3$

DOF for interaction $=3 \times 1 \times 1=3$

Minimum no. of simulations=Total DOF $(3+3)+1=7$

(

The Latin Square with symbol $\mathrm{L}_{\mathrm{n}}\left(\mathrm{m}^{\mathrm{f}}\right)$ is used as an OA representation where $\mathrm{L}$ stands for Latin Square and $\mathrm{n}$ is the total number of experimental or simulation runs, m represents the number of level per factor and $f$ is the number of factors. The Taguchi $\mathrm{L}_{8}\left(2^{7}\right)$ OA satisfies the minimum required number of simulations based on the DOF criterion [24]. The assignment of two levels for each of the three control factors based on references $[14,17,23]$ and is as summarized in Table
Table A.2

Assignment of 2-level control factors

\begin{tabular}{cccc}
\hline \hline \multirow{2}{*}{ Control Factor } & \multicolumn{2}{c}{ Level } \\
\cline { 3 - 4 } & & 1 & 2 \\
\hline A & PSV $_{\text {in }}(\mathrm{m} / \mathrm{s})$ & 0.2 & 0.7 \\
B & R & 0.71 & 0.84 \\
C & $\alpha($ Degree $)$ & 20 & 80 \\
\hline \hline
\end{tabular}

A total of 7 control factors with two levels each can be assigned to the $\mathrm{L}_{8}\left(2^{7}\right) \mathrm{OA}$. The $\mathrm{L}_{8}$ linear graph as shown in Fig.A.2 was used as a guide to assign each control factor to a column in the OA layout. The dots represent control factors and the line connecting the two dots represents the interaction between the two associated control factors. Since there are three control factors under our investigation, only three columns will be assigned i.e. columns 1, 2 and 4 whereas column 3, 5, 6 and 7 were left empty so that their two-way interactions can be assessed. The interactions between columns 1 and 2, 1 and 4 and 2 and 4 appear in column 3, 5 and 6 respectively. Column 7 is not connected to any control factor and therefore considered as an independent point or it can be used to estimate three-way interactions.

\section{A.2.}




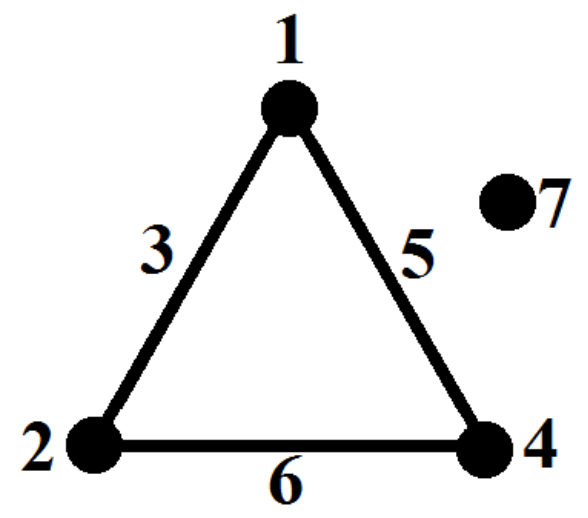

Fig.A.2. L8 Linear Graph

In our studies, interactions between $\mathrm{V}_{\text {in }}$ and $\mathrm{R}, \mathrm{R}$ and $\alpha$; and between $\alpha$ and $V_{\text {in }}$ appear in column 3, 5 and 6 respectively as shown in Table A.3.

Table A.3

L8 Orthogonal array

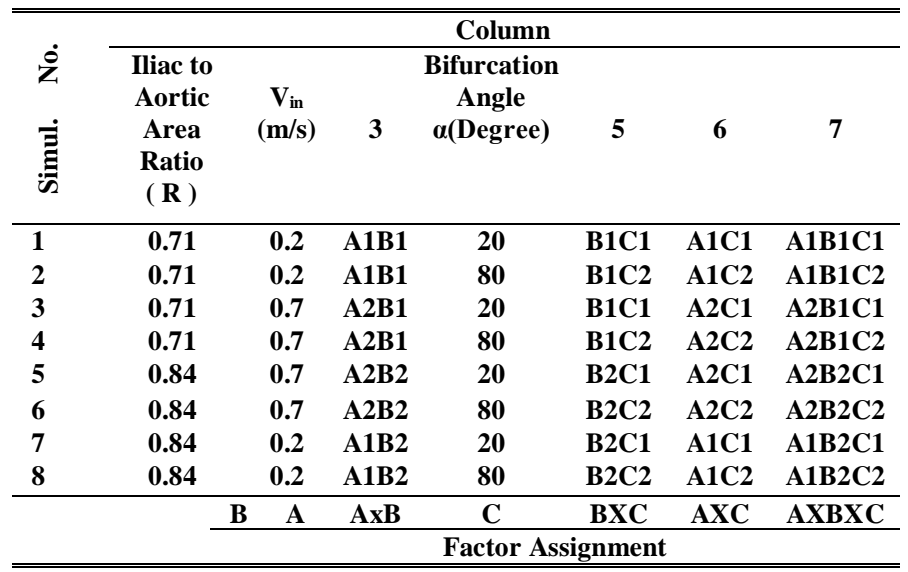

\section{Appendix B: Computational Fluid Dynamics}

\section{Inlet Boundary Condition}

A pulsatile boundary condition was prescribed as the inlet velocity. Its profile was derived from [17] with a cardiac cycle of 0.93 second and PSV of $0.45 \mathrm{~m} / \mathrm{s}$ at 0.14 second. The cardiac cycle of 0.93 second was kept however $\mathrm{PSV}_{\text {in }}$ of 0.2 $\mathrm{m} / \mathrm{s}$ and $0.7 \mathrm{~m} / \mathrm{s}$ were used in these studies therefore the profile in the vertical axis was scaled proportionally. Fig.B.1. shows the pulsatile inlet velocity profile with a $\mathrm{PSV}_{\text {in }}$ of 0.7 $\mathrm{m} / \mathrm{s}$ and the black dot indicates the $\mathrm{PSV}_{\text {in }}$ at 2.0 second in the third cardiac cycle.

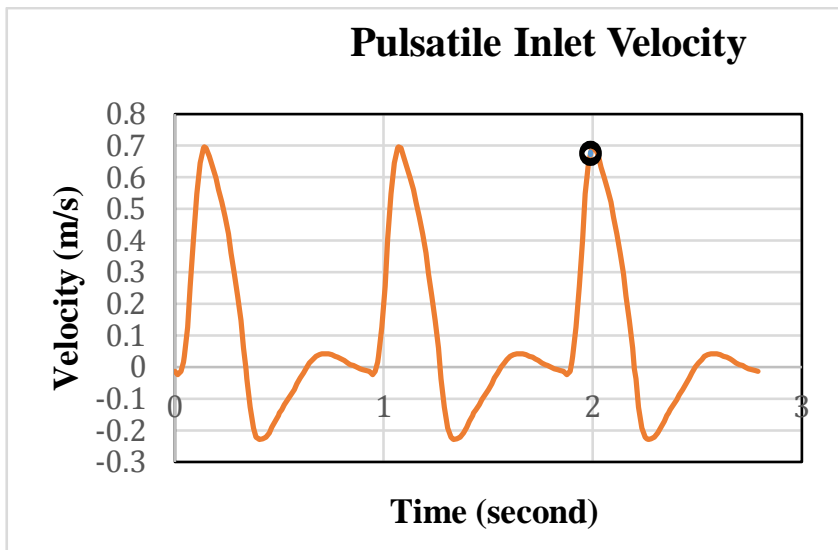

Fig.B.1 Pulsatile inlet velocity profile with a $\mathrm{PSV}_{\text {in }}$ of $0.7 \mathrm{~m} / \mathrm{s}$ and the black dot indicates the PSV in at 2.0 second in the third cardiac cycle

\section{Entrance length to Evaluate Velocity Profile}

A $220 \mathrm{~mm}$ long cylinder with $20 \mathrm{~mm}$ diameter was used to evaluate entrance length required to establish fully developed velocity profile. The cylinder was created by SolidWorks CAD software and meshed with Fluent Meshing tools and then CFD simulation was performed by ANSYS Fluent 17.0 software using $0.2 \mathrm{~m} / \mathrm{s}$ as Plug Flow Velocity $\left(\mathrm{PFV}_{\text {in }}\right)$ at the inlet, as shown in Fig. B.2. Velocity profiles at $20 \mathrm{~mm}$ 
intervals from the inlet were evaluated and it took about $120 \mathrm{~mm}$ for the velocity profile to fully develop in the first cardiac cycle. However, the second and subsequent cardiac cycles did not fully develop into parabolic profile up to $220 \mathrm{~mm}$ at the end of the cardiac cycle due to pulsatile nature of $\mathrm{PFV}_{\text {in }}$ In all subsequent transient CFD simulations, entrance length of $180 \mathrm{~mm}$ was introduced to obtain a realistic velocity profile in the infra-renal aortic region. PSV at $180 \mathrm{~mm}$ from the inlet was then defined as the infra-renal PSV or PSV in as defined in Appendix A, Fig.A.1. The ratio of $\mathrm{PFV}_{\text {in }} / \mathrm{PSV}_{\text {in }}$ for the $3^{\text {rd }}$ cardiac cycle was found to be 0.927 in the cylinder model. For example, by applying a $0.927 \mathrm{~m} / \mathrm{s} P F V_{\text {in }}$ at the Inlet, $\mathrm{PSV}_{\text {in }}$ of $1 \mathrm{~m} / \mathrm{s}$ can be expected at $180 \mathrm{~mm}$ from the Inlet.

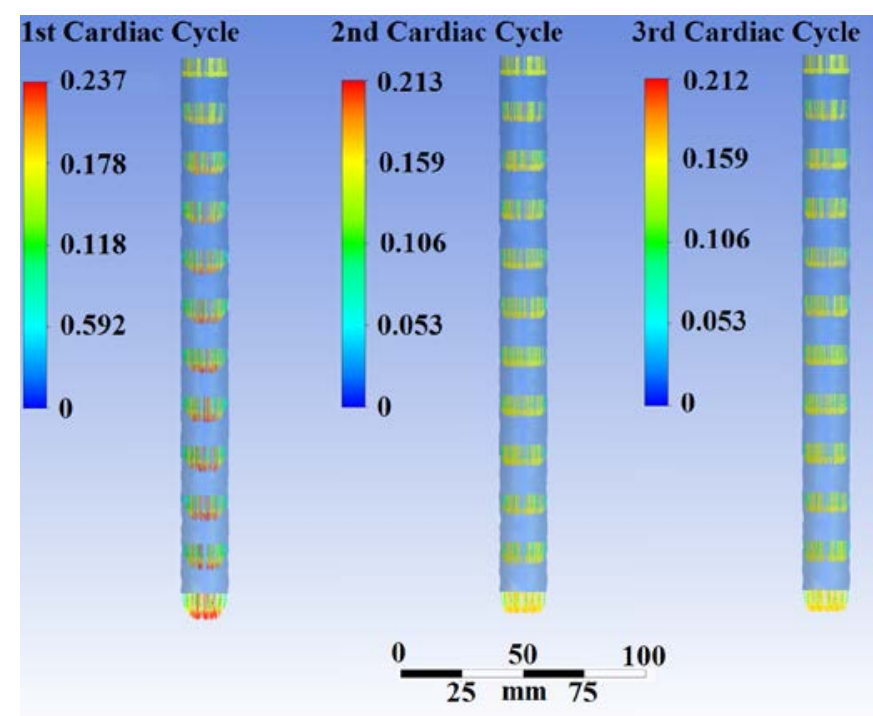

Fig. B.2. Velocity Profile Evaluated at $200 \mathrm{~mm}$ Entrance Length Intervals from Inlet

\section{Reading PSV $V_{\max }$ in the Stented Segment}

$\mathrm{PSV}_{\max }$ was obtained from CFD simulation by examining the velocity vectors in Common Iliac Arteries (CIA) in the stented segment $50 \mathrm{~mm}$ downstream from the bifurcation as shown in
Fig. B.3. After each CFD simulation, $\mathrm{PSV}_{\text {in }}$ was checked to see if the desired value was achieved. Minor adjustment to inlet Plug Flow Velocity $\left(\mathrm{PFV}_{\text {in }}\right)$ was made where necessary to achieve the desired $\mathrm{PSV}_{\text {in }}$ and CFD simulation was repeated accordingly.

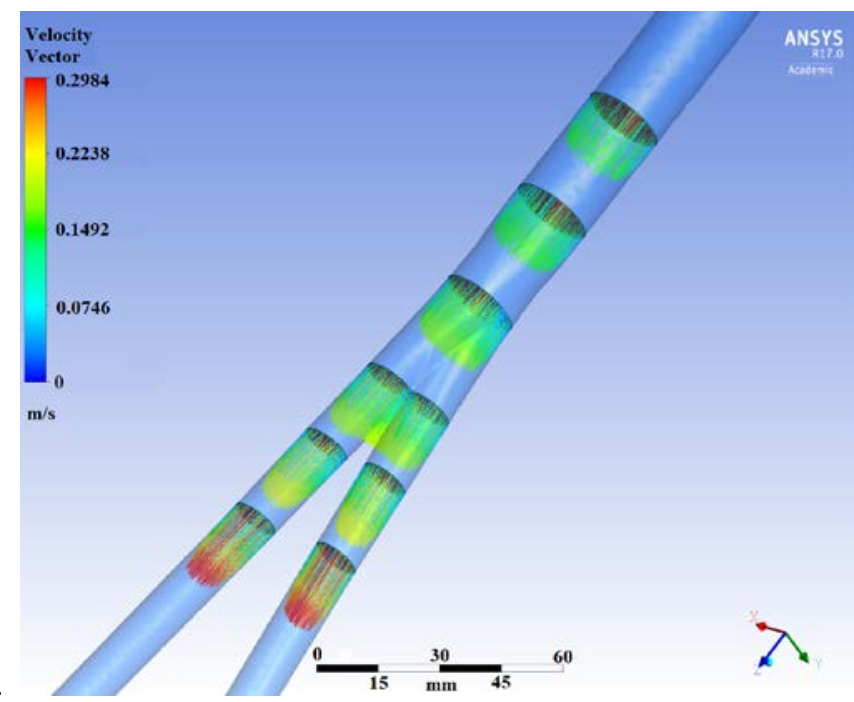

Fig. B.2. Instantaneous velocity profiles in the aortoiliac bifurcation model at peak inlet velocity

\section{Grid Independence Tests.}

Polyhedral elements with boundary layers were meshed using unstructured Fluent meshing due to improved computational convergence and reduced computation time as compared with tetrahedral elements proposed by Spiegel et al [25]. Four types of meshes coarse, medium, fine and finer were used to test grid convergence which was shown in Table B.1. The CFD simulation was assumed to have achieved grid independence when further refinement of cells resulted in less than $1 \%$ change in the parameter of interest, in our case, $\mathrm{PSV}_{\max }$. Fine mesh with minimum $0.5 \mathrm{~mm}$ cells and about 100,000 elements were used in all the CFD simulations performed on a Dell Precision T1700 desktop computer (Dell Computer, Round 
Rock, Texas, U.S.A.), with a typical 1 hour computation time running 8-cores in parallel.

\section{Table B.1}

Grid independence test

\begin{tabular}{ccccc}
\hline \hline $\begin{array}{c}\text { Mesh } \\
\text { Type }\end{array}$ & $\begin{array}{c}\text { Min. } \\
\text { Cell } \\
(\mathbf{m m})\end{array}$ & $\begin{array}{c}\text { Cell } \\
\text { Count }\end{array}$ & $\begin{array}{c}\text { PSV }_{\max } \\
(\mathrm{m} / \mathrm{s})\end{array}$ & $\begin{array}{c}\text { Change } \\
\mathbf{( \% )}\end{array}$ \\
\hline Coarse & $\mathbf{1 . 5}$ & $\mathbf{6 5 , 2 4 5}$ & $\mathbf{0 . 8 9 3}$ & $\mathbf{2 . 5 4}$ \\
\hline Medium & $\mathbf{1 . 0}$ & $\mathbf{7 3 , 8 6 1}$ & $\mathbf{0 . 9 1 5}$ & $\mathbf{1 . 3 0}$ \\
\hline Fine & $\mathbf{0 . 5}$ & $\mathbf{9 6 , 6 7 7}$ & $\mathbf{0 . 9 2 7}$ & $\mathbf{0 . 8 2}$ \\
\hline Finer & $\mathbf{0 . 2 5}$ & $\mathbf{1 2 4 , 9 8 2}$ & $\mathbf{0 . 9 2 0}$ & \\
\hline \hline
\end{tabular}

\section{Periodicity Convergence Test}

The simulation was assumed to have achieved its periodicity when the changes in PSVmax at various time-steps are less than $1 \%$ from the previous cardiac cycle. Table B.2 shows periodicity reached in the third cardiac cycle.

Table B.2

Periodicity convergence test

\begin{tabular}{|c|c|c|c|}
\hline $\begin{array}{c}\text { Cardiac } \\
\text { Cycle } \\
\text { (0.93s } \\
\text { Period) }\end{array}$ & $\begin{array}{c}\text { Time } \\
\text { Step } \\
\text { (s) }\end{array}$ & 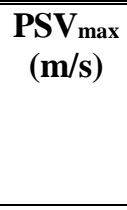 & $\begin{array}{c}\text { Change } \\
(\%) \\
\text { from } \\
\text { previous } \\
\text { period } \\
\end{array}$ \\
\hline \multirow{3}{*}{ First } & 0.14 & 0.998 & \\
\hline & 0.15 & 1.002 & \\
\hline & 0.40 & 0.463 & \\
\hline \multirow{3}{*}{ Second } & 1.07 & 0.903 & 9.52 \\
\hline & 1.08 & 0.911 & 9.08 \\
\hline & 1.33 & 0.420 & 9.29 \\
\hline \multirow{3}{*}{ Third } & 2.00 & 0.898 & 0.55 \\
\hline & 2.01 & 0.908 & 0.33 \\
\hline & 2.26 & 0.419 & 0.24 \\
\hline \multirow{3}{*}{ Forth } & 2.93 & 0.898 & O \\
\hline & 2.94 & 0.908 & O \\
\hline & 3.19 & 0.419 & $\mathbf{0}$ \\
\hline
\end{tabular}

